\title{
Ondine syndrome
}

INSERM

\section{Source}

INSERM. (1999). Orphanet: an online rare disease and orphan drug data base. Ondine syndrome. ORPHA:661

Congenital central hypoventilation syndrome (CCHS) is a rare disease due to a severely impaired central autonomic control of breathing and dysfunction of the autonomous nervous system. The incidence is estimated to be at 1 of 200000 livebirths. A heterozygous mutation of PHOX-2B gene is found in $90 \%$ of the patients. Association with a Hirschsprung's disease is observed in $16 \%$ of the cases. Despite a high mortality rate and a lifelong dependence to mechanical ventilation, the long-term outcome of CCHS should be ultimately improved by multidisciplinary and coordinated follow-up of the patients. 